\title{
DESCONSTRUIR PARA EDIFICAR: UMA VISÃO ACERCA DA INFÂNCIA E UMA PROPOSTA PARA SUA COMPREENSÃO ATRAVÉS DA CHAVE DA MUDANÇA
}

Laryssa Frezze e Silva

Resumo: O presente trabalho buscará refletir sobre o papel da educação na formação do indivíduo, considerando para isso o lugar da escola na sociedade atual, o que se espera dessa instituição e como ela pode vir a intervir na dinâmica social que vivemos. O artigo está dividido em três seções; primeiramente, discute-se acerca da necessidade de modificação do sistema educacional brasileiro, fato que já é tomado como inquestionável, mas cuja aplicabilidade é sempre posta em xeque. Usamos como fundamento idéias de Walter Benjamin, Theodor Adorno e Ligia Averbuck. Depois fala-se brevemente sobre o construtivismo e, por fim, há um estudo de comparação entre dois programas televisivos infantis veiculados pela TV Cultura em diferentes épocas, quais sejam "O Castelo Rá-tim-bum" e "O Quintal da Cultura". O objetivo desse estudo é o de comparar as diferentes visões de infância que cada programa apresenta e, a partir disso, fazer um julgamento de valor.

Palavras-chave: Infância; Sociedade; Educação; Respeito; Mudança.

Resume: This paper aims to reflect on the role of education in shaping the individual, specially when it comes to the place of the School in today's society, to what is expected of this institution and to how it is likely to intervene in the social dynamics in which we live. The article is divided into three sections; First, we discuss about the need for modification in the Brazilian educational system, a fact that is already taken for granted, but which applicability is always called into question. We use as basis the ideas of Walter Benjamin, Theodor Adorno and Ligia Averbuck. Then we speak briefly about Constructivism and, finally, there is a comparison study between two children's TV programs broadcasted by TV Cultura at different times, namely "O Castelo Ra-TimBum" and "O Quintal da Cultura". The aim of this study is to compare the different visions of childhood presented by each program and, from that, make a value judgment.

Keywords: Childhood; Society; Education; Respect; Change. 
"Dado todavia que, como mostra a psicologia profunda, os caracteres em geral, mesmo os que no decorrer da existência chegam a perpetrar os crimes, já se formam na primeira infância, uma educação que queira evitar a reincidência haverá de concentrar-se na primeira infância" (ADORNO, Theodor. "Educação após Auschwitz" ${ }^{1}$ )

"É preciso não trapacear com a criança" (TREVISAN, Armindo. In “A criança e a poesia" ${ }^{2}$ ).

Já é lugar-comum em nosso país assumir que qualquer mudança efetiva que se almeje nas estruturas da sociedade há de ser direcionada, primeiramente, à instância da educação. As novas gerações carregam, desde o lluminismo e a burguesa organização familiar que se estabelece ao redor da criança, as promessas de um novo futuro, melhor e mais igualitário, em que as características mais virtuosas do homem pudessem suplantar as falhas mais terríveis de sua natureza.

Uma educação preocupada com a formação de novos indivíduos e voltada para a primeira infância é algo relativamente novo na história da humanidade e esteve sujeita a inúmeros erros - dentre os quais talvez o principal seja o excesso de moralismo (o que me parece uma expressão redundante, mas que se mostra necessária, tendo em vista que tratamos de um grande excesso) imposto às crianças desde a partir da mais tenra idade. Acerca disso, nos fala um pouco Walter Benjamin em seu ensaio "Velhos livros

1 ADORNO, Theodor. "Educação após Auschwitz" in Theodor W. Adorno - sociologia. Organizador: Gabriel Cohn. Editora Ática, São Paulo. s/ data.

${ }^{2}$ TREVISAN, Armindo. Citado por AVERBUCK, Lígia "A poesia e a escola" in ZILBERMAN, Regina Org. Leitura em crise na escola. Porto Alegre: Mercado aberto, 1985. Pp 63-83. 
infantis", em que o livro infantil pode ser entendido como metonímia para todo o processo de educação:

"O livro infantil alemão - assim começa a introdução à sua história - nasceu com o lluminismo. Com sua forma de educação os filantropos colocaram à prova o imenso programa de formação humanitário. Se o homem era piedoso, bom e sociável por natureza, então deveria ser possível fazer da criança, ser natural por excelência, o homem mais piedoso, mais bondoso e mais sociável. E como em todas as pedagogias teoricamente fundamentadas a técnica da influência objetiva só foi descoberta mais tarde e aquelas advertências problemáticas constituíam o início da educação, assim também o livro infantil tornou-se, nos primeiros decênios, moralista, edificante e variava o catecismo e a exegese no sentido do deísmo" (BENJAMIN, Walter. "Velhos livros infantis", pp. $49-50)$.

O homem, que via em si um ser vicioso e incompleto, buscava reprimir desde cedo na criança aquilo que seu pensamento social intuitivamente the mostrava como vil e danoso à sociedade. Sua busca pela criação de sujeitos melhores, portanto, encontrou - desde os primórdios - vazão na repressão dos instintos naturais e não numa reflexão acerca deles, de modo que à criança também cabia o desconforto social sem que se entendesse - de uma ou de outra parte - a razão para tal desconforto. Assim se instituiu um processo de prevenção: antes que o indivíduo se tornasse desvirtuado, a educação haveria de incutir nele os valores sociais necessários para a formação de um cidadão capaz de adentrar a ordem social e de reproduzi-la, mas não de questioná-la, pois o questionamento era desrespeitoso e configurava um tabu.

Ainda hoje é assim, muito se tem discutido acerca da educação no Brasil e em todo mundo. Mas aí está a questão: pensa-se numa educação ideal como aquela que propicia ao aluno uma oportunidade para refletir sobre si e sobre seu contexto, num exercício de interpretação, realmente, da parte ao todo e do todo à parte. No entanto, o que temos hoje é, na grande maioria, uma educação que prioriza a repetição das normas e dos meios cristalizados - a qual não tem por objetivo a criação de indivíduos criativos (ou talvez, em teoria, até o tenha, mas na prática simplesmente não consegue alcançá-lo, pois emprega as mesmas técnicas arcaicas, embora espere resultados diferentes), mas sim a de sujeitos que reproduzem o sistema. 
Mas o sistema não está dando certo - e já temos consciência disso há algum tempo. Esse tema, inclusive, tem sido frequentemente abordado em muitas discussões e pelas mais diversas camadas sociais. Ora fala-se da situação dos docentes, ora da condição física das escolas, da realidade social dos alunos, da diferença entre escolas privadas e públicas ou da posição que o Brasil ocupa em rankings internacionais. Qualquer que seja o enfoque dado, fala-se de educação: todas as pessoas sabem que em nosso país há um grave problema nessa área, mas ninguém consegue dizer com clareza do que se trata, ou apontar soluções para o mesmo. Em paralelo, reconhecemos que o problema não se restringe à escola e está também presente, numa dimensão ainda mais ampla, em nossa sociedade.

Estamos a reproduzir padrões de comportamento os quais mostram-se falhos, reincidindo em erros. Sabemos disso, é-nos evidente o grande impasse que vivemos. Mais ainda, compreendemos até que a forma mais acertada de reparo está ligada à educação - principalmente em se tratando das séries mais baixas, as pré-escolares. Mas, intuição acertada à parte, não sabemos o que fazer com essa informação.

O presente trabalho não se pretende mostrar como profundo conhecedor do caminho a ser seguido no percurso de solução do problema. Antes, busca refletir sobre o mesmo, de forma análoga à que tem sido feita por outros pensadores brasileiros, tendo por base teorias afins e, talvez, tatear uma saída da pegajosa situação em que nos metemos, quando tratamos da educação. Temos claro que a solução do problema há de ser iniciada, indubitavelmente, nas séries mais baixas do programa educacional e que uma grande mudança há de ser feita em todo o sistema, a partir daí, para que os erros que vêm se reproduzindo possam, ao médio e longo prazo, ser saldados até a situação ideal da não-ocorrência.

Temos nas mãos a seguinte situação: se buscamos alunos mais criativos e engajados no entendimento de sua realidade, precisamos criar situações para que a criatividade seja incentivada - cotidianamente. É exatamente sobre isso o que fala Lígia Morrone Averbuck em seu ensaio "A poesia e a escola". De acordo com Averbuck, a poesia deve ocupar papel 
central na educação de crianças, se com ela se pretende criar espaço para indivíduos mais inventivos. No entanto, isso não ocorre presentemente em nosso sistema educacional. Na verdade, a poesia é vista como algo marginal no percurso de aprendizado por não ser considerada séria ou mesmo necessária para a dinâmica da vida que se impõe ao sujeito ao longo de sua existência. Diz ela: "É, possivelmente, neste aspecto de gratuidade da poesia que estará a base de sua exclusão das áreas ditas "sérias" dos conhecimentos, o que, certamente, é inspirado numa visão utilitarista e pragmática da educação e da vida em geral." (AVERBUCK, Lígia Marrone. 1985 pp. 65-66).

E, mais adiante:

"Numa organização selada pelo utilitarismo, cada criança deve aprender a não perder seu tempo, nem tomar o de seus professores. "O jogo", lembra Roudinesco, "é o lazer, e o lazer é o "erro" do repouso", onde o agradável é o "útil", o tempo perdido é, para o capital, como para a escola, proscrito porque sem lucro. A poesia e a arte em geral participam dessa área "não lucrativa" onde se inserem as atividades prazerosas e lúdicas, excluídas do programa de vida de uma sociedade voltada para o ganho.

Como os problemas da escola estão intimamente relacionados com os da sociedade no seu conjunto, pode-se perguntar em que medida a sociedade, com sua organização e seu sistema estanque de relações, sufoca a imaginação criadora dos jovens e em que medida a escola participa desse estiolamento, em vez de estimular a capacidade de criar, como deveria ser seu papel”. (AVERBUCK, Lígia Marrone. 1985, pp. 65-66).

Ou seja, ao se limitar a um universo de cumprimento de pautas, de reprodução de idéias pré-estabelecidas que não dão espaço para a criação, a escola faz casa ao projeto capitalista de eficiência e alienação, mas não forma indivíduos pensantes e capazes de buscar seus lugares sociais de maneira criativa.

De fato, o que ocorre é que esperamos que a escola cumpra um certo papel na sociedade, qual seja o da produção de um ambiente propício ao desenvolvimento de indivíduos plenos e criativos, capazes de modificar a presente realidade social. Mas não nos apetece a elaboração de formas para que esse lugar se concretize. Seria possível que esperemos da escola os 
consertos que até agora não conseguimos efetuar? Seria possível que a instituição-escola sofra, de forma expiatória, da condenação pelas falhas sociais que não encontram solução? Não acredito ser um fato ignorado que se se efetivarem as mudanças basilares na educação, toda a sociedade, ao longo prazo, sofrerá as consequências dessa mudança - para o bem ou o mal dela. Se, de fato, forem consumadas reformas que modifiquem a estrutura educacional e, digamos, dêem enfoque maior ao ensino e estímulo de entendimento da poesia, estaremos criando sujeitos capazes de questionar a realidade em que vivem. $E$ talvez, só talvez, tenhamos medo da in-surgência desses sujeitos.

Priorizar a arte na educação pode vir a modificar a visão corrente o que, por ventura, pode ocasionar uma tentativa de subverter a ordem vigente. Há um medo subentendido de canalizar essa energia questionadora, capaz de modificar tradições arcaicas e nocivas, mas conhecidas e confortáveis. Por conta disso, essas tradições são protegidas e as convenções estabelecidas na educação das crianças são perpetuadas (retomemos aqui, por exemplo, a questão do moralismo) - ainda que não prestem favores, de fato, a ninguém: nem à sociedade, nem ao indivíduo.

$E$, no entanto, é justamente nesse contexto que a já referida priorização se faz da maior importância. Afinal, repetidamente o sistema que perdura temse mostrado falho. Repetidamente também há um clame da sociedade para que a educação cumpra um papel na criação de indivíduos criativos. Há de se entender, portanto, que fazer eco a uma dinâmica tecnocrata e permitir cada vez mais a entrada na sociedade de pessoas que reproduzam o sistema não é o papel esperado da educação.

Precisamos ensinar poesia, não porque precisamos "fabricar" poetas, mas porque se faz urgente possibilitar a entrada na sociedade de indivíduos capazes de empatia, de sensibilidade comunicativa. Acerca disso, Averbuck cita:

"Nos dizeres do poeta Jerome Rothemberg, 'a poesia imita o pensamento ou a ação. Ela propõe seu próprio deslocamento. Permite a vulnerabilidade e o conflito. Permanece como a melhor ciência, constantemente aberta à mudança, a uma contínua troca em nossas idéias do que um poema é ou 
pode ser. $\mathrm{O}$ que é a linguagem. $\mathrm{O}$ que é a experiência. $\mathrm{O}$ que é a realidade. Ela tornou-se, para muitos de nós, um processo fundamental para o jogo e a troca de possibilidades."” (AVERBUCK, Lígia Marrone. 1985, p. 67).

Em resumo, o que se coloca é o seguinte: todos estamos cientes da insatisfação corrente que está agregada às estruturas de nossa sociedade. $\mathrm{E}$, se queremos uma coletividade melhor, devemos criar condições para que melhores sujeitos possam ser formados. Sujeitos passíveis de entender a si próprios e ao contexto que os circunda de forma engenhosa e que consigam propor mudanças, porque não são parte do problema. No entanto, é preciso que tenhamos de forma clara a noção de que, ao propor e fazer tais mudanças válidas e efetivas, estaremos acionando modificações sérias e precisaremos estar cientes das consequências que advirão a partir daí. Consequências tais como uma sociedade mais igualitária em direitos e passível de priorizar interesses muito diversos dos que têm sido priorizados ao longo de nossa história. Estaríamos prontos para isso, para sair do estado de privilégios que se naturalizou em nossa nação, apesar dos sérios esforços que têm sido feitos nos últimos anos para que tal estado não se perpetue?

Muita coisa se modificaria e talvez não seja do interesse de grupos politicamente mais fortes que tais mudanças se efetivem. Para os grupos que se encontram do lado positivo de um sistema de privilégios, o interessante é a perpetuação de uma sociedade técnica, que saiba cumprir ordens e tenha 0 domínio mínimo das operações matemáticas e da leitura para que o cumprimento seja satisfatório. ${ }^{3}$

Mas já foi dito: a samsara da tecnocracia não nos satisfaz. Contrariamente, nos consome. Somos os que não estão do lado positivo dos privilégios e conseguimos empatizar, ainda, com tantos outros em situações ainda mais críticas do que a nossa: trabalhadores explorados, frutos de uma educação precária, que os fada a somente inserirem-se na engrenagem para o pleno funcionamento da máquina, da qual nunca tirarão proveito. Fazem-se,

${ }^{3}$ ZILBERMAN, Regina "Literatura e sociedade burguesa" in A literatura e o ensino da literatura. Editora Contexto, coleção Repensando o ensino. 1985. 
portanto, necessárias as tais mudanças, justamente porque a partir delas, minimamente, põe-se em xeque o tipo de cidadão que queremos perpetuar e, por consequência, o tipo de sociedade que queremos no futuro. Daí, a partir da crise eminente, pode-se conseguir grandes resultados, podem-se modificar estruturas inteiras a fim de que as mudanças culminem em conquistas concretas.

Ao dar à arte em geral e à poesia em particular um lugar de importância na formação dos indivíduos permite-se que o que seja constantemente questionado seja o próprio sujeito, de modo a que se pense que esse não é infalível - assim como não o são suas estruturas sociais, seus dogmas, verdades e mitos. Questionando-se o sujeito pode-se questionar o que vai ao seu redor. Só assim uma estrutura mais justa poderia ser criada. O conhecimento da poesia leva a um maior conhecimento da linguagem, que é o meio pelo qual as pessoas entendem a si mesmas e ao mundo.

Nesse sentido, cabe a pergunta "Mas por que há de se priorizar a educação infantil?". A resposta me parece lógica: se há alguns anos, o ímpeto da educação moralizante era justamente o de reprimir os impulsos indesejados desde a tenra idade, parece-me apenas razoável que o ímpeto de uma nova educação centrada no auto-conhecimento também queira lançar mão de lastros plantados em terra fértil e passíveis de se aprofundar e fortalecer por toda uma existência.

Tendo isso em mente, podemos levar em conta a proposta sócioconstrutivista, que encontra embasamento nas idéias de Jean Piaget e Vigotsky. De acordo com Maria Fernandes Cócco e Marco Antônio Hailer,
"segundo pesquisas piagetianas, o desenvolvimento cognitivo se dá pela assimilação do objeto do conhecimento a estruturas anteriores do sujeito e à acomodação dessas estruturas em função do objeto a ser assimilado. Para Piaget, aprender é modificar, descobrir, inventar. A função do professor é propiciar situações para que o aluno construa seu sistema de significação, 0 qual, uma vez organizado na mente, será estruturado no papel ou oralmente.
O sócio-construtivismo é uma teoria que vem sendo desenvolvida a partir dos estudos de Vigotsky e de seus seguidores. Esses estudos sobre aquisição da linguagem como fator histórico e social enfatizam a importância da interação e da informação linguística para a construção do conhecimento. O centro do 
trabalho passa a ser, então, o uso e a funcionalidade da linguagem, o discurso e as condições de produção. O papel do professor é o de mediador, de facilitador que interage com os alunos através da linguagem num processo dialógico." (CÓCCO, Maria Fernandes e HAILER, Marco Antonio. 1994. 2)

E, mais adiante:

"A instituição escolar, de maneira geral, tem realizado um trabalho com texto que prepara o educando para ler e escrever narrações, dissertações, descrições e cartas. Ele é treinado para reproduzir textos modelares, com regras fixas pré-estabelecidas e numa linguagem escolar distante da realidade. Esse trabalho geralmente leva 0 aluno a decodificar sem compreender e escrever sem expressividade.

A exploração de textos diversificados - verbais e extra-verbais - é uma prática pedagógica que proporciona o desenvolvimento da expressividade, do uso funcional da linguagem, da leitura e da reflexão sobre o mundo". (CÓCCO, Maria Fernandes e HAILER, Marco Antonio. 1994. 2)

Dessa forma podemos entender que a proposta sócio-construtivista prega a abordagem dos conhecimentos através da diversidade da linguagem e, assim, vai muito ao encontro do que temos discutido até aqui, principalmente em se tratando das idéias difundidas por Lígia Averbuck.

Nesse sentido, gostaria de propor um exercício de comparação entre dois programas de TV voltados ao público infantil, ambos veiculados pela TV Cultura - em épocas diferentes - e que se pregam como educativos. Um deles, o "Castelo Rá-tim- bum", série exibida ao longo dos anos 90, define sua proposta pedagógica como construtivista; o outro "O Quintal da Cultura", no ar pela mesma emissora na atualidade, não prega nenhuma diretriz pedagógica específica, mas afirma que assistir a programas de TV pode vir a contar positivamente no desenvolvimento infantil, caso se trate de um programa de TV de qualidade.

Comecemos tratando do Castelo. A estréia do "Castelo Rá-tim-bum" provocou um aumento de treze pontos no ibope da TV Cultura - o que foi posteriormente interpretado como uma prova de que dava certo investir bastante num programa infantil de qualidade. Trata-se de uma série de TV 
voltada para um público-alvo em idade escolar e com a proposta de preencher lacunas na educação que as crianças recebem na escola.

O Castelo conta com seis personagens fixos, oito convidados e integrantes de quadros e onze fantoches. $O$ enredo básico do programa fala do seguinte: Nino, um menino aprendiz de feiticeiro de trezentos anos de idade (interpretado por um adulto, cabe dizê-lo) atrai com feitiçaria outras três crianças para o castelo, pois não tinha com quem brincar e se sentia solitário. A partir desse episódio, as três crianças Pedro, Biba (uma menina negra colocada numa posição que valoriza sua feminilidade e beleza) e Zequinha passam a visitá-lo todos os dias e convivem com as criaturas e demais moradores e visitantes do castelo.

A atração contava com diversos quadros, alguns relacionados à música em suas diversas formas (divulgação de diferentes sons em diferentes instrumentos musicais, canto, coreografias de dança moderna, leitura de partitura etc.), outros à poesia (visita das crianças ao Gato Pintado, guardião da biblioteca), ciências (O quadro dos cientistas gêmeos Tíbio e Perônio), contação de estórias, sapiências (como o ratinho que toma banho e o quadro "Lavar as mãos") e até um outro quadro chamado "Porque sim não é resposta!", em que uma pergunta nunca deixava de ser respondida, porque é preciso saldar as dúvidas, não importando a natureza delas, já que todas têm uma razão de ser. Além de outros. Eram quadros curtos, contando com no máximo cinco minutos de duração e que, em conjunto, contabilizavam episódios de cerca de uma hora.

A importância do Castelo Rá-tim-bum, em minha opinião, é a de colocar a visão infantil do mundo num lugar respeitável e de importância, gozando de grandes incentivos financeiros, numa vasta e competente equipe de artistas e técnicos e um balanço delicado entre entretenimento e conteúdo - de modo a não tornar o conhecimento e sua obtenção algo pedante e sem sentido, porque não é contextualizado na realidade cotidianamente vivenciada pela criança. $\mathrm{A}$ criança - e isso é claro até para o olhar infantil que assiste ao programa - é reconhecida como um ser complexo, o que pode ser percebido pelo imenso 
cuidado despendido a cada quadro, à trilha sonora e até mesmo à vinheta de abertura da programação ${ }^{4}$

Além disso, de forma muito despretensiosa, a criança acabava por travar contato com artistas importantes do cenário cultural nacional, como Arnaldo Antunes, Paulo Leminski, Cecília Meireles, Manuel Bandeira, Vinícius de Moraes, Mário Quintana, dentre outros. A cultura brasileira, personificada no personagem da Caipora, é apresentada de forma natural e orgânica - o que permite um reconhecimento por parte da criança. Em tempo, as criançaspersonagens Pedro, Biba e Zequinha têm enfoque cênico e oportunidade de falar e interagir com os adultos que os respeitam como indivíduos. Mesmo a interpretação do personagem do Nino, um menino de trezentos anos, que é feita por um adulto é realizada de forma respeitosa, sem que o ator faça papel de bobo na tentativa de se igualar a uma criança. Além disso, personagens negros e brancos convivem sem qualquer desconforto e são postos em situações de igualdade. E questões como a convivência com as diferenças sempre priorizam a empatia e a necessidade de entender a realidade diversa do outro antes de poder julgá-lo (é o caso do personagem do Etvaldo e da Zula).

Ao longo dos episódios, sempre que uma situação de ensinoaprendizado é retratada, há uma clara distinção entre alunos e mestres. Via de regra, os mestres são sempre os personagens adultos, como a feiticeira Morgana, tia-avó de Nino, o Tio Victor e o Gato Pintado (que é um fantoche, de fato, mas cuja personalidade é equivalente a de um adulto). No entanto, o ensinamento nunca é feito de forma autoritária, mas sim convidativa. Quando

\footnotetext{
${ }^{4}$ A vinheta de abertura do Castelo: Uma árvore cresce e dela saem raios de luz (pozinhos mágicos?) que fecundam a terra e montam a estrutura do castelo ao redor da árvore. Ouve-se a sílaba "cas". Depois vêm as colunas (ao fundo ouve-se "cas" e "té") e aí vêm as paredes, enquanto a música soa "bum, bum, bum, castelo". Seguem-se a escada, a torre, as janelas, a cúpula da torre e a música ao fundo faz "cas" e "té" e "bum, bum, bum". Vêm as gárgulas ("tim, tim, tim) e continua "bum, bum". Vêm as antenas "tim, tim". Daí, do chão, sai um robozinho e, de dentro dele, uma mão mecânica que se estende até o alto, à cúpula da torre (e a música acompanha o movimento "caaaaaas"). A mão coloca uma bandeira, em que se lê "Castelo Rátim-bum" no alto da torre e música se completa: "Bum, bum, bum Castelo Rá-tim-bum". A vinheta é muito interessante, porque é como se mostrasse que o castelo vai se formando a partir de uma conjunção de magia e palavras que, ao final, harmonicamente, se completam.
} 
Morgana conta suas estórias com fundo moral para Adelaide, não faz de forma a reprimi-la, mas a aconselhá-la para que suas ações mudem antes que algo de ruim resulte de um pensamento que não antevê as consequências dos próprios atos.

Em resumo, é uma atração infantil que reconhece a criança como sujeito, dá-lhe amplo acesso à poesia e às outras formas de arte e incentiva uma vivência e um comportamento que priorizem a arte como meio de entendimento do mundo. Além disso, insere a criança em seu meio urbano, porém passível de imaginação e magia. E o vilão, o personagem que deve e é combatido e desmascarado episódio após episódio, o Doutor Abobrinha, é um sujeito capitalista que quer comprar o terreno do Castelo para construir um estacionamento de cem andares com o qual possa lucrar exorbitantemente. Ou seja, a partir do que foi brevemente exposto, podemos também concluir que trata-se de um programa que ensina os valores que devem ou não ser acatados para o surgimento de uma sociedade melhor, mas o faz de forma fluida, com respeito e sem imposições autoritárias. ${ }^{5}$

Em contrapartida, falemos do "Quintal da Cultura", programa que está na grade atual do mesmo canal. Trata-se de uma série diária que vai ao ar ao vivo e que conta com cinco personagens fixos e dois fantoches com os quais interagem. Não há um roteiro fixo, mas sabe-se, por exemplo, que os personagens guardam relações de parentesco entre si. Ludovico e Dorotéia são irmãos; Filomena, Osório e Teobaldo são primos. Eles são espécies de clowns que moram num quintal monocromata que muito se diferencia da pluralidade cênica do Castelo. Mas as diferenças não param por aí. 0 programa não é orgânico; há algo de árido e artificial nele e parece tentar seguir tendências veiculadas por programas infantis canadenses e norteamericanos - notadamente "Lazy Town”, "Barney" e outros afins. Isso, em si, já é um problema, porque esses programas tendem a subestimar a inteligência

\footnotetext{
${ }^{5}$ Informações mais completas acerca desse pensamento podem ser encontradas no documentário localizável a partir do seguinte endereço virtual, acessado em 27 de Novembro de 2014: https://www.youtube.com/watch?v=u7Xu 8euXKQ.
} 
das crianças e reduzi-las a pessoas muito pouco inteligentes. Não é exagero. Examinemos alguns quadros.

Há um episódio em que os personagens Dorotéia e Ludovico propõe às crianças convidadas que participem de uma ciranda. Primeiramente, há de se notar que nem as crianças estão empolgadas. Depois, quando começam a "cirandar" e alguns dos meninos começam a cantar músicas propícias, são severamente repreendidas por Dorotéia que diz "sem cantar! Então mudo!". E, depois de rodarem em silêncio, sugere "uma música, e se a gente ouvisse uma música?" e aí começa a tocar uma música velha sobre cirandas, a qual às crianças não tange cantar, porque não a conhecem. E sua espontaneidade foi absolutamente repreendida em detrimento de uma outra forma expressiva cujo valor foi claramente elevado, por se tratar de uma música relacionada à tradição. ${ }^{6}$

Mas há um outro quadro um tanto mais perturbador, o da professora Dorotéia. Nesse, Dorotéia se veste de professora e passa a dar aula para seus bonecos e bichinhos de pelúcia. O que faz é uma mistura muito infeliz de muitos dos perfis professorais descritos no texto de Adorno "Tabus acerca do magistério" 7 . Vemos desde o professor exausto ao despótico, do repressor ao agressivo e, em resumo, nada do que vemos nessa encenação demonstra qualquer situação de sala de aula aceitável. No entanto, é posta como algo naturalizado (e até engraçado), o que é minimamente assustador. Bem, Dorotéia, que dava aula aos seus bichinhos de pelúcia, entra em sala reclamando do comportamento de seus alunos. Toda vez que não se comportam como o previsto, a professora os pega, sacode, ameaça de os enviar para a diretoria e depois os joga violentamente para fora de cena. Os alunos são retratados nesse quadro como sem voz, não podem defender-se das acusações feitas pela professora, que é histérica. Manda os alunos, um a um para a diretoria, porque estão soltando gases na sala de aula - e, no final,

${ }^{6}$ Quadro da ciranda, "Quintal da Cultura", localizável a partir do seguinte endereço virtual, acessado em 27 de Novembro de 2014: https://www.youtube.com/watch?v=09pc4PI1FTg

7 ADORNO, Theodor. "Tabus acerca do magistério" in Educação e emancipação. São Paulo, Paz e Terra, 1995. 
descobre que foi ela mesa que estava soltando os tais gases. Ou seja, culpa os alunos e os pune por sua própria falta - e, volto a dizer, esse tipo de atitude é naturalizado e tido como engraçado.

Os atores do "Quintal da Cultura", todos adultos, interpretam crianças, mas o fazem, via de regra, salvo algumas desafogantes exceções - como a interpretação do personagem Ludovico, por exemplo -, de maneira desrespeitosa. A criança é interpretada como um ser estúpido, "chatinho" e as brincadeira as quais se dedica são igualmente aborrecidas e maçantes (o que talvez queira encontrar justificativa no fato de os personagens serem palhaços, ou de se tratar de um programa cujo público alvo é o pré-escolar, ou por ser ao vivo mas que, de fato, nada justifica). Os quadros são entrecortados por desenhos de franquias estrangeiras, como a Nickelodeon e o Discovery Kids, de forma que não existe uma continuidade temática ao longo dos episódios. Mesmo a eventual abordagem de poesias é feita de forma clichê e nãoestimulante. Exemplo disso, é a interpretação do poema "Ou isto ou aquilo", de Cecília Meireles, em cujas cenas as personagens simplesmente repetem com gestos aquilo que as palavras já dizem. ${ }^{8}$

O "Quintal da Cultura" quer propor a si mesmo como um programa propício e indicado ao público infantil. No entanto, não compreende o próprio público que quer alcançar e divulga uma idéia de infância como um período de conflitos menores, personalidades fixas, perguntas estúpidas ("Levanta para cima ou para baixo?") e preconceitos. Quer se propor também como um programa integrador de diversas realidades - e o faz, em certa medida, com o cuidado que tem, por exemplo, em divulgar a linguagem de libras para as crianças surdas-mudas. No entanto, falha ao subestimar a inteligência das crianças que se sentem enganadas, pois sua imagem no programa não é satisfatória e não corresponde à realidade.

Em comparação com o Castelo, deixa muito a desejar, uma vez que não segue o exemplo do programa anterior, o qual proporciona ao espectador uma

\footnotetext{
${ }^{8}$ Quadro do "Quintal da cultura", poema de Cecília Meireles "Ou isto, ou aquilo", localizável a partir do seguinte endereço virtual, acessado em 27 de Novembro de 2014: https://www.youtube.com/watch?v=ghBjmQThfOk.
} 
avalanche de vivências artísticas com o intuito de inspirá-lo a entender o seu espaço através dessa linguagem. O "Castelo Rá-tim-bum", em minha opinião, vai ao encontro da proposta educacional sugerida por Lígia Averbuck, qual seja a de educar com poesia. O "Quintal da Cultura", por outro lado, não o faz, pois propaga comportamentos naturalizados em nosso imaginário acerca da educação infantil, mas os quais deveriam ser modificados, principalmente em se tratando da relação professor-aluno e da forma autoritária e despótica com que ela, via de regra, é retratada no programa. Isso não é engraçado, é perturbador. As crianças aprendem a se comportar por repetição e exemplo e se esse é o exemplo que o programa tem a dar, seria melhor que repensassem seus quadros e as vertentes pedagógicas que norteiam toda a programação.

Como fim desse exercício de comparação, gostaria de propor que professores assistam aos dois programas e também os comparem com base nos critérios os quais abordamos aqui. Além disso, em se tratando do bom exemplo do "Castelo Rá-tim-bum", acho válido utilizar seus quadros para propor atividades em sala de aula. Por exemplo, pode-se citar o quadro do Mau e do Godofredo, duas criaturas (fantoches) que vivem nos encanamentos do Castelo. O Mau sempre propõe charadas que, se não forem respondidas, darão vazão a sua terrível "gargalhada fatal", para o horror de Godofredo, que entra na brincadeira fazendo com o que o Mau acredite que ele é realmente terrível e assustador e que sua gargalhada é, de fato, fatal. A partir desse quadro, uma maratona de charadas pode ter início. As crianças podem se reunir em grupos e criar charadas entre si, ou pesquisá-las em casa e depois desafiarem-se.

Uma outra atividade que pode ser proposta a partir dos quadros do Castelo e que também vai ao encontro à proposta construtivista, diz respeito ao quadro "Fazer acontecer"', em que se explica a forma de criação das mais diversas coisas, desde armações de óculos, até a pipa e o vidro. A partir dele,

\footnotetext{
9 Quadro "Fazer acontecer" do "Castelo Rá-tim-bum", localizável a partir do seguinte endereço virtual, acessado em 27 de Novembro de 2014: https://www.youtube.com/watch?v=KCi2rGXDh4g.
} 
pode-se propor às crianças que pesquisem em casa como se faz qualquer coisa acerca do que elas nutrem alguma curiosidade sobre o processo de feitura. As crianças podem, num dia previamente marcado, trazer suas pesquisas e compartilhá-las com os colegas. Há nesse exercício, implicitamente, um incentivo à independência e à curiosidade, um senso de responsabilidade (há uma data para trazer o trabalho), além de uma noção de que o conhecimento deve ser compartilhado.

Enfim, tudo isso foi exposto com o intuito de demonstrar que é possível propor e executar mudanças, se tivermos a plena consciência acerca delas, das modificações que advirão, dos problemas passíveis de ser enfrentados e dos resultados que serão obtidos. Também é necessário analisar a situação atual e as ferramentas disponíveis, de modo a utilizá-las da forma mais sábia possível. É preciso que fique claro que as mudanças no método educativo atual fazem-se necessárias, porque mesmo as dinâmicas sociais mostram-se insatisfatórias. A forma de mudança que provavelmente trará os melhores resultados diz respeito à educação.

Se não quisermos continuar a reproduzir pessoas apáticas e técnicas, precisamos modificar o processo de formação dessas pessoas. Ou, como diria Adorno em seu artigo "Educação após Auschwitz",

"Receio que através de medidas educativas, por mais abrangentes que sejam, será difícil evitar que assassinos de escrivaninha tornem a aparecer. Mas que existem pessoas que lá embaixo, como servos, portanto, praticam atos que se destinam a perpetuar a sua própria servidão e se despem de toda a dignidade humana; que continuem existindo Bogers e Kaduks, contra isso se pode fazer alguma coisa, pela educação, pelo esclarecimento". (ADORNO, Theodor. p. 45).

É preciso educar pela poesia, pela arte, se quisermos ver qualquer mudança. E não devemos com ela, como diz Averbuck, esperar que se ensinem boas maneiras, o bom senso, a bela linguagem. Devemos esperar que ela torne o oculto acessível, que a criança possa se familiarizar consigo mesma até o entendimento. 
"E é por essa via que se estabelece como prática privilegiada da liberdade, espaço individual e forma de aprofundamento das relações sociais. Seu pleno desenvolvimento na escola só se realizará, contudo, no limite da alteração das regras escolares, de reformulação integral da forma de conceber a criança, o homem e seu papel no mundo. Por aí supomos, se estabelecerão novos caminhos." (AVERBUCK, Lígia Marrone. 1985 p. 83).

Que se alterem as regras e que a criança seja reconhecida como indivíduo pensante, cuja formação tem de ser totalmente voltada a sua futura entrada na sociedade adulta, de forma a que possa atuar e questionar-se acerca dessa sociedade, buscando sempre modificá-la, exercendo o papel de cidadão e sabendo conviver consigo mesmo e com os outros de forma harmoniosa. Esse deveria ser o ideal máximo da educação. Mas há muito trabalho a ser feito.

\section{BIBLIOGRAFIA:}

ADORNO, Theodor. "Educação após Auschwitz". In: COHN, Gabriel (org.). Theodor W. Adorno - sociologia. São Paulo: Editora Ática, s/ data.

ADORNO, Theodor. "Tabus acerca do magistério". In: ___. Educação e emancipação. São Paulo: Paz e Terra, 1995.

AVERBUCK, Lígia. "A poesia e a escola”. In: ZILBERMAN, Regina (org.). Leitura em crise na escola. Porto Alegre: Mercado aberto, 1985, pp. 63-83.

BENJAMIN, Walter. "Velhos livros infantis". In: Reflexões: a criança, o brinquedo, a educação. São Paulo: Summus, 1984.

CÓCCO, Maria Fernandes e HAILER, Marco Antonio. "Orientações para o professor". In: ALP: análise, linguagem e pensamento. A diversidade de textos numa proposta sócio-construtivista. (Livro 7). São Paulo: Editora FTD, 1994. 
ZILBERMAN, Regina. "Literatura e sociedade burguesa". In: A literatura e 0 ensino da literatura. São Paulo: Editora Contexto, 1985 (Coleção Repensando o Ensino).

ANEXOS:

(I) CASTELO RÁ-TIM-BUM:

Todos os videoclipes aqui sugeridos foram acessados em 27 de Novembro de 2014:

- Videoclipes de excertos de episódios do Castelo para os poemas e música de Arnaldo Antunes:

https://www.youtube.com/watch?v=LwhW7Uw7Fp8 (“Lavar as mãos");

https://www.youtube.com/watch?v=kOedZ8Mlwbo $\quad$ (“Tudo”);

https://www.youtube.com/watch?v=hNbvFGBdFdQ (“As árvores");

- Videoclipes de excertos de episódios do Castelo para os poemas de Vinícius de Moraes:

https://www.youtube.com/watch?v=ItdiYRwH3Oo $\quad$ ("O relógio");

https://www.youtube.com/watch?v=buFTcutl3NQ ("A galinha d'angola");

https://www.youtube.com/watch?v=nQfx9zl6HnE (“A porta");

- Videoclipe do excerto de um episódio do Castelo para o poema de Manuel Bandeira:

https://www.youtube.com/watch?v=4UWWxXUab7M ("Trem de ferro")

- Videoclipes de excertos de episódios do Castelo para os poemas de Mario Quintana:

https://www.youtube.com/watch?v=h4bfKDxh5Do ("O paciente distraído")

https://www.youtube.com/watch?v=i73WqDLEOXM ("Hai kai")

https://www.youtube.com/watch?v=czcKIknoHz8 ("A casa em ruínas”) 
- Videoclipes de excertos de episódios do Castelo para os poemas de Paulo Leminski:

https://www.youtube.com/watch?v=BmKVY2V5ejU ("Caprichos e relaxos")

https://www.youtube.com/watch?v=CWDCtgmw7P4 ("Polonaise")

- Videoclipes de excertos de episódios do Castelo para os poemas de Cecília Meireles:

https://www.youtube.com/watch?v=LRa7mF6W2B4 ("O eco")

https://www.youtube.com/watch?v=UFLOcbSn2E4 ("Bolhas")

- Videoclipe do excertos de um episódio do Castelo para o poema de Ferreira Gullar:

https://www.youtube.com/watch?v=byayKU51kC0 $\quad$ ("Ocorrência")

\section{- Documentários:}

https://www.youtube.com/watch?v=tugZDzr48f0 ("Making of Castelo Rá-tim-bum!")

https://www.youtube.com/watch?v=u7Xu 8euXKQ ("Desconstruindo o Castelo - O Boom do Rá-Tim-Bum")

https://www.youtube.com/watch?v=g7wgR1YtEXU ("Entrevista com Cao Hamburger, criador e diretor do Castelo Rá-Tim-Bum!")

- Quadro "Passarinho, que som é esse:

https://www.youtube.com/watch?v=9F-8iZmSOFc $\quad$ (O piano)

https://www.youtube.com/watch?v=-t8avEob1gU (A flauta transversa)

https://www.youtube.com/watch?v=BDYQmzoAb88 (A viola caipira)

https://www.youtube.com/watch?v=tJrsM2wz4jQ $\quad$ (A trompa)

https://www.youtube.com/watch?v=w2ctynPtVSA $\quad$ (A cítara) 
(II) QUINTAL DA CULTURA:

Todos os videoclipes aqui sugeridos também foram acessados em 27 de Novembro de 2014:

\section{Quadros:}

- "Serra, serra, serrador":

https://www.youtube.com/watch?v=yfLUb476HKE.

- “Coelhinho da páscoa existe?":

https://www.youtube.com/watch?v=GBXii2DjOxA

- "Fui morar numa casinha":

https://www.youtube.com/watch?v=17-ahYh-oxc

- "O bilboquê":

https://www.youtube.com/watch?v=1e cbx0fxmQ

- "O sapo não lava o pé":

https://www.youtube.com/watch?v=CGs6uvlzHFk

- "Professora Dorotéia":

https://www.youtube.com/watch?v=fQRQetJDbpU

- "Professora Dorotéia - A prova surpresa":

https://www.youtube.com/watch?v=GrAyzZiDzRM

- “Especial Tatiana Belinky":

https://www.youtube.com/watch?v=u9LmfFJQYfo

- “Poesia no varal":

https://www.youtube.com/watch?v=wxZUvZdBR8A

- "Brincando com poesia - Cecília Meireles":

https://www.youtube.com/watch?v=quzu5v5ojRM 
- "Brincando com poesia - Manuel de Barros"

https://www.youtube.com/watch?v=quzu5v5ojRM

- "Você quer ser minha namorada?"

https://www.youtube.com/watch?v=Ey3ruRMzM4Q

- "Secretária - Carta alterada":

https://www.youtube.com/watch?v=p108vaNJO3Y

Informações obtidas no site do programa:

- $\quad$ Sobre o Quintal da Cultura:

http://tvcultura.cmais.com.br/quintaldacultura/sobre-o-quintal-da-cultura

- Público alvo:

http://tvcultura.cmais.com.br/quintaldacultura/perfil-publico

- Diretrizes pedagógicas:

http://tvcultura.cmais.com.br/quintaldacultura/diretrizes-pedagogicas/qual-opapel-da-tv-no-desenvolvimento-infantil

Outras Informações:

http://ciaprosadosventos.blogspot.com.br/2011/04/quintal-da-cultura.html;

https://conexaotvaudiencia.wordpress.com/2014/04/15/quintal-da-cultura-baterecorde-de-audiencia-nesta-segunda-14/ 